\title{
A QUALITATIVE TEST FOR SOUR SOILS.
}

\author{
BY NORMAN M. COMBER.
}

\author{
(Department of Agriculture, The University, Leeds.)
}

Since the publication in 1914 of the results obtained by Daikuhara (2) in an investigation of certain acid soils of Japan, considerable prominence has been given in the literature of Soil Chemistry to the presence of iron and aluminium salts in the solution of sour soils.

Harris(1) had demonstrated the possibility of aluminium being removed from the relatively non-reactive part of soils and kaolins, and then to be held in such a manner that it is practically resistant to water, but is partially and appreciably interchangeable with the cation of a neutral salt. The occurrence of iron and aluminium salts in certain pine forest soils, which have been covered with "raw humus," is described by Kappen (5,6), and Spurway (7) has discussed the different ratios of easily soluble calcium oxide to iron and aluminium oxides which obtain in acid and alkaline drift soils. A similar alteration in the ratio of the oxides of calcium and magnesium to those of iron and aluminium, accompanying an alteration in reaction, has been shown by Howard (11) in some soils of the Rhode Island Agricultural Experiment Station.

The value of the analytical data respecting the causal association of iron and aluminium salts with soil acidity is greatly enhanced by the work of Hartwell and Pember $(9,10)$ which demonstrates the similar effects of aluminium sulphate and the extracts of acid soils on the growth of plants, and the dissimilar effects of sulphuric acid and either the aluminium salt or the soil extract.

The consistent indication of the above-mentioned work is towards the following general conception. The soil reactions (to discuss the nature of which is no part of the present purpose) make on the reactive part of the soil a demand for bases. This demand is normally met, in most soils with which we are acquainted, by calcium and magnesium compounds; but it is met by less suitable compounds of iron and aluminium when the supply of available calcium and magnesium compounds is temporarily depleted, and when the soil solution, being no longer basic in reaction, can admit iron and aluminium by ionic interchange. 
The association of aluminium with the "sourness" of the medium of plant growth seems to find further support in the work of Stoklasa (8). This investigator has shown that aluminium occurs in relatively large a.mounts in the Hydrophytes, whose habitat will generally be more sour than that of the Xerophytes which contain only small traces of aluminium. It would appear here, that plants which normally grow in wet places are acclimatized to the effects of aluminium.

If it is generally true that in sour soils the cations in the soil solution replace iron and aluminium from their salts absorbed in the reactive surface of the soil particles, then any sour soil, when treated with a neutral solution of a potassium salt, may be expected, in the exchange of cations, to give up some amount of iron to the solution. If the potassium salt used is the thiocyanate, the fact of iron going into solution can be qualitatively demonstrated forthwith by the appearance of the red colour of ferric thiocyanate.

In quite another connection, the writer recently had occasion to apply a solution of potassium thiocyanate to various soils of known character, and it was incidentally noticed that the red colour appeared only when the solution was applied to acid soils. The solution applied to non-acid soils remained colourless.

In furtherance of this observation six soils which had been found by the Hutchinson-MacLennan method not to absorb calcium bicarbonate were taken at random from the departmental soil stores, together with six others known to have lime requirements which had been determined $^{1}$ by the same method to be $0.03,0.06,0.07,0.11,0.15$ and $0 \cdot 17$ per cent. $\mathrm{CaCO}_{3}$ respectively. About $2-3 \mathrm{gm}$. of each of the twelve soils were placed in test-tubes and about 5 c.c. of a bench solution of potassium thiocyanate were added. The solution in contact with each of the soils having a lime requirement was found to be pink or red within an hour, while no trace of pink colour was seen in the other six cases, even after standing for three weeks. In two cases (those with lime requirements of 0.03 and 0.06 per cent. $\mathrm{CaCO}_{3}$ ) the pink colour was not apparent at first and, while indubitably present, was not very pronounced after an hour. The test was therefore repeated with these twelve soils using an alcoholic solution of potassium thiocyanate, since

\footnotetext{
1 Most of the soils referred to in this paper had been sampled by Dr J. A. Hanley by whom the lime requirements had been determined and kindly placed at the writer's disposal. The results are taken here for their qualitative rather than their quantitative value, for there is no intention of implying any particular opinion that may be held by the writer, or by his colleague, of their quantitative meaning.
} 
it was expected, on both physical and chemical grounds, that the concentration of the ferric thiocyanate in the liquid phase would be increased by making this alteration. A great improvement in the delicacy of the test resulted. In five minutes all the soils had settled leaving clear solutions which were emphatically red or pink over the soils deficient in lime and quite colourless over the remainder.

In further confirmation of the test thirty-six soil samples were taken at random from the above-mentioned collection of Yorkshire soils. Twelve showed no lime requirements by the Hutchinson-MacLennan method, and twenty-four showed lime requirements varying from 0.03 to 0.30 per cent. $\mathrm{CaCO}_{3}$. These were tested with an alcoholic solution of potassium thiocyanate containing $40 \mathrm{gm}$. thiocyanate in a litre of 95 per cent: alcohol. Distinct pink or red colours obtained in those solutions which were in contact with the soils capable of absorbing calcium bicarbonate, while the remainder were quite colourless.

The test has subsequently been applied to various soils brought into the laboratory for examination in respect of lime requirement, and has correctly predicted in every case whether or not the soil would absorb calcium bicarbonate.

Altogether over 70 soils have so far been examined by the thiocyanate test, and without exception those which absorb lime have been identified; indeed, one soil, stated to have a lime requirement of 0.035 per cent. $\mathrm{CaCO}_{3}$, gave no pink colour with the thiocyanate, and this led to the discovery of a clerical error whereby the soil had been wrongly described as having a lime requirement.

Ammonium thiocyanate in equivalent amount is much less sensitive than the potassium salt. This, of course, would be expected from van Bemmelen's observations of the relative rates of exchange of ions between hydrous silicates and solutions. Both the ammonium and potassium salts are much less sensitive in aqueous solution than in alcohol. An alcohol-ether solution of thiocyanate is much more sensitive than an alcoholic solution, but the latter gave a satisfactory indication in the cases examined. An alcohol-ether solution is useful for borderline cases.

It is concluded that if $2-3 \mathrm{gm}$. of a soil are placed in a test-tube and vigorously shaken with about 5 c.c. of a concentrated alcoholic solution of potassium thiocyanate, the development of a pink or red colour in the solution, which increases on standing, will indicate, qualitatively, a deficiency of lime in the soil. If the colour is very faint it may be more easily seen after filtering. A definite alkalinity of the soil may be 
confirmed by adding a few gm. of the soil to an alcoholic solution of thiocyanate which is rendered slightly pink by a trace of ferric thiocyanate. The pink colour will be removed if the soil is alkaline.

The reaction involved in this test is essentially an exchange of ions and not an ordinary dissolution of some soluble iron compound. This was shown by taking some of the soils which gave a colour with aqueous thiocyanate, shaking them with water for five minutes and then filtering the solution into a test-tube containing thiocyanate crystals. No pink or red colour developed.

The colour of the ferric thiocyanate in the solution over the soils deepens visibly for about 48 hours, and the final equilibrium is probably only established after a much longer period (see Leiningen, KolloideZeitsch. 1916, 19, 165). But it is clear that even after equilibrium is finally established, the colour cannot be used as a comparative measure of the lime requirement of different soils; for only iron is identified in this test, in a mixture of iron and aluminium in proportions which will vary from one soil to another. Other reasons also preclude a quantitative interpretation of the colour. On the same soil however the test may afford useful indications of the variation of acidity. Two cases may be quoted in illustration.

The thiocyanate test was applied to soil samples taken from different parts of a field on the Leeds University Farm at Garforth, and one area was found by the test to have no lime requirement. This was afterwards identified with the place of a chalking experiment in 1911.

In another instance a bare patch on one of the University lawns in the city of Leeds was sampled, and separate samples were collected from the soil $0^{\prime \prime}-3^{\prime \prime}$ from the surface, $3^{\prime \prime}-6^{\prime \prime}$ from the surface and $6^{\prime \prime}-9^{\prime \prime}$ from the surface. Treated with alcoholic thiocyanate solution, the soil of the top $3^{\prime \prime}$ immediately induced a red colour in the solution, while the samples from greater depths did not. A column of this soil from which the surrounding soil had been dug away, was then divided into half-inch layers, by means of a nickel spatula, to a depth of $2 \frac{1}{2}$, and soil from each of the five layers was tested with alcoholic thiocyanate solution. The soil of the top half-inch gave an opaque blood red colour to the solution immediately, the next layer gave a red colour, the third layer a pink colour, and the remainder gave no colour at all. The acidity was thus shown to be intensively confined to the surface layer of soila circumstance easily correlated with "smoke damage." 


\section{BIBLIOGRAPHY.}

(1) Harris, J. E. Journ. Phys. Chem. 1914, 18, 355.

(2) Daikuhara, G. Bull. Imp̈. Cent. Agric. Exp. Sta. Japan, 1914, 2, 1.

(3) RUPRECHT, R. W. Mass. Agr. Exp. Sta. Éull. 161, 125.

(4) MIYAKE, K. Journ. Biol. Chem. 5, 19, 335.

(5) KAPPEN, H. Landw. Versuchs-Stat. 1916, 88, 13.

(6) — Ibid. 1916, 89, 39.

(7) Spdrway, C. H. Journ. Agric. Res. 1917, 11, 659.

(8) StokLasa, A. Biozbem. Zeitsch. 1918, 88, 292.

(9) Hartweil, B. L. and Pember, F. R. Soil Sci. 1918, 6, 259.

(10) — Journ. Amer. Soc. Agron. 1918, 10, 45.

(li) Howard, L. P. Soil Sci. 1919, 8, 313.

(Received 18th May, 1920.) 